\title{
Bilingual Khmer/English Literature: Contestation Practices and Strategies in the Cambodian Literary Field
}

\author{
Fransiskus Tri Wahyu Setiawan ${ }^{1}$
}

\begin{abstract}
The study aims to examine how different agents namely individuals, groups, and organizations form the Cambodian literary field compete through selected practices. Certain strategies are applied in accordance to the rules of game in the literary field production. Having different habitus and capitals, agents struggle and compete for positions in the literary field. Applying literary study and classical ethnographic methods this study shows that political distance from the government in the field of cultural production allows external forces to interfere and reshape the Cambodian literary field. Agents make the structure and are structured in dynamic competition within the field. Strategies are mainly intended to create new network and to gain legitimacy, thereby accumulating capitals. Bilingual Khmer/English literature is important literary phenomenon in Cambodia as it indicates practices of contestation in response to the global field of cultural production
\end{abstract}

Keywords: Cambodian Literary Field, Capital Conversion, Cultural Production

\footnotetext{
${ }^{1}$ Graduate Student at Universitas Gadjah Mada, Yogyakarta, Indonesia. This research was conducted as part of the In Search Balance program; a cooperation between Universitas Gadjah Mada and the University of Adger, with the support of the Embassy of Norway. Corresponding e-mail: fransiskus.tws19@gmail.com
} 


\section{Introduction}

The development of literature in Cambodia has been indicated by several chronological orders. They are: the period of traditional literature, marked by Sanskrit and Pali letters (Jacob, 1996, p. 9); the early modern literature period under French protectorate; the period of post-Khmer Rouge modern literature (Nepote \& Dy, 1981, p. 61); and the period modern contemporary literature (Yamada, 2016, p. ix). During those periods, different dynamics and power exercises within the Cambodian field of literature have heavily influenced the development of literature as art and as means of expression.

This research employs Bourdieu's theory of 'field' of cultural production. For him, culture is the locus of power exercises involving different structures and agents with different resource compositions (Bourdieu, 1993, p. 37). Moreover, his concept of 'habitus' is also illuminating since it explains the trajectory of practices, based on reasonable choices accumulated through long, albeit not fully conscious, experience forming a durable and transposable abstract entity (Bourdieu, 1996, p. 170). Every agent in the field acquires various forms of capital - economic, cultural, social, and symbolic resources - through recognition (Bourdieu, 1986, p. 47; 1990, p. 128). In this regard, a form of capital is potentially converted into the other forms when agents inhabit certain positions in the field through which such conversion is depended upon. All these Bourdieusian concepts reveal how the operation of power works within the arena of cultural production and significantly shapes the structure of the contemporary Cambodian literary field.

One notable disruption of the Cambodian literature development period was the Pol Pot regime during 1974-1979 (Chandler, 1993, p. 210). The regime had caused political instability, economic depression, and cultural losses for Khmer society. According to Stewart and May (2004, p. ix) the Khmer Rouge period has been considered as the worst condition for Cambodian literature production. The regime destroyed the country's libraries and Cambodia's rich written and oral heritage. This created a trauma in Cambodian society, one which (together with various other obstacles) contributed to the difficult circumstances in developing culture, literature, education, publishing, and literacy (Miller, 2016) in attempting to rebuild the country. 
Despite the trauma living in Khmer society, the recent generation of Cambodians are now trying to rebuild and regain an existence literary (Yamada, 2016, p. x), by adapting the current situation and pushing the limit to express their thoughts. In this context, several groups have contributed to the most recent development of literature, including Nou Hach Literary Association (NHLA), Cambodian Living Arts (CLA), Slap Paka Khmer (SPK), Poets Playwrights Essayists Editors Novelists (PEN) Cambodia, and Scholar Library. Indeed, emerging writers, including Channpal Sok, Chheangly Yeng, Chin Meas, Phina So, and Monica Sok, have played an essential role in the field of literary cultural production who have made a mark on modern contemporary Cambodian literature.

The pressure on free expression of ideas through the media is still in the air. The Media in Cambodia (Strangio, 2017, p. 80) elucidates clearly about the current media landscape of Cambodia and the landscape is much more complex than the legal institutional framework alone suggests. The sense of censorship reaches deeply into the minds of Cambodian society, including young writers. They write under an anxious feeling as their writing activity brings them under scrutiny of the authorities in charge. However, to stop writing is definitely not an option. Hence, writers and other organizations within the field of literary practice certain strategies to survive and to attract external attention in navigating the difficult circumstances.

Rebuilding Cambodian cultural production together with its relevant elements has been predominantly relying on various forms of foreign aids. Indeed, Cambodia has been flooded with donor institutions, agencies, and non-governmental agencies (Guillou, 2013, pp. 404-405) focusing primarily on the issues of developing infrastructure, health, food security, as well as other pillars such as education and literature.

A range of activities has been crafted to promote literacy and literature. Those activities - for example the Kampot Writers and Readers Festival, Cambodia National Book Fair, Meet Authors Forum, and other activities such as small group discussions and inter-writer sharing - have been a field through which powers and capitals are exercised and exchanged. Agents actively cooperate in making relations from various occupied positions, negotiate, and compete for accumulating capitals which enable them to conduct certain practices with a purpose to retain their most profitable position within the cultural field. 
NHLA, as an institution fully concerned with literature, conducts several programs to persuade an arrangement in Cambodian field of literature. The programs include activities in providing training for new writers, assisting Cambodian writers for publication, organizing an event called the Nou Hach Literary Competition (NHLC), and translating the Khmer literature works into English. Those activities have been able to produce groups of active and productive new authors, for instance Yeng Cheangly who writes poetry and publishes the Khmer/English bilingual anthology In the Shadow. Other authors, including Chanpal Sok, Phina So, Achariya Hang, Sina Soy, Venerable Meas Chin, and Dara Lim, are actively involved in literary activities and events in Cambodia.

The appearance of bilingual Khmer/English publications has become a signal of modern contemporary Cambodian literature. It is a distinct characteristic which marks the difference to previous literature in Cambodia. Thus, it reflects dynamics within the field of literature in terms of changing relations, different agents composition, transforming power, new practices applied, or any other possible causes and circumstance which facilitate such form of serving literary work.

An inquiry of its occurrence offers a doorstep to observe the forming field of literature through agents' power relations and negotiation. Foreign intervention and local resistance can be seen in the formation of new groups or new events in responding and adapting the current circumstances, as actors struggle and compete to acquire rewards from and within the literary field. Agents aim at reproducing valuable positions or achieving better positions in the literary field while promoting the development of national literature.

The field of cultural production shows that art is not merely the product of a genius artist or reflects the needs and demands of certain classes in society. Bourdieu argues that specific sets of relations cause certain works of art to come into production. The 'field' is a locus of forces and struggles through which agents within the field seek to accumulate capitals under certain relations of power. In practice, each agent is influenced by their 'habitus', which is internalized, embodied, and turned into second nature (Bourdieu, 1990, p. 63). The process of decision or responses may be made consciously or unconsciously. Limitations or regulations on what can (or not) be undertaken are sometimes accepted by existing agents in the field. Agents' need for converting capitals into different forms of capital depend on 
their position within the field they are situated. Hence, certain choices are made under the influence of their positions and the capitals they acquire.

\section{Literature Review}

Reading relevant literature has been conducted to provide framing of the situation in contemporary Cambodia and its literature. The Handbook of Contemporary Cambodia (Brickell \& Springer, 2017, p. 4) presents general information on the situation of Cambodia in present time, including its politics and economy, rural development, urban conflicts, social processes, and cultural currents. "Just a Human Being" and Other Tales from Contemporary Cambodia (Yamada, 2013, p. viii) provides an insight on the position of young writers in Cambodia's modern contemporary literature, despite of their difficulty in writing up their ideas. Moreover, Publishing in Cambodia (Jarvis, Lalonde, \& Lakhena, 2006, p. 17) statistically examines the situation of Cambodia's publishing industry and its possible directions for development. In the Shadow of Angkor: Contemporary Writing from Cambodia (Stewart \& May, 2004, p. ix) provides a picture of Cambodian literature in the past and its experiences with repression, ultimately showing Cambodia's struggles in gaining existence through writing. The Emergence of Twentieth Century Cambodian Literary Institutions: The Case of Kambujasuriya (Chigas, 2000, p. 137) examines the changing features and classifications of Khmer literary works in the journal Kambujasuriya, managed by the Buddhist Institute, thereby providing a notion of how institutions may play a role in the on-going progress of building modern literature.

This reading leaves some questions that require further investigation and different perspectives in describing the phenomena in Cambodia. Why is literature not presented, despite it being a dominant art in the great Khmer civilization? What strategies are applied by young writers as they negotiate with existing forces? How significant are publishers in promoting literacy and literature? What forms of work represent Cambodia's modern contemporary literature? How do organizations practices shape the developments and changes in Cambodia's literature? Lastly, why is literature seemingly ignored as a priority for the country's human resource development? 


\section{Research Method}

This research combines literary study and ethnography using both written discourses and factual accounts in the field. The literary study (Hart, 2011, p. 16) involves close reading of related resources about the history of Cambodia, the development of Cambodian literature, its features and writers, social situation, and literary events. The ethnography method involves participant observation (Spradley, 1980, p. 53) and virtual ethnography (Hine, 2001, p. 63), offering flexibility in and outside the field with control over the link between target audiences and their online accounts (Hine, 2005, p. 11).

Data gained from the aforementioned methods is grouped into categories. The division is based on the need to discuss: 1) the field of cultural production and its relation to the field of power; 2) the forming of new habitus in literature and its features; 3 ) the practices and strategies used by agents in the literary field; and 4) forms of capital conversion. Together, these are intended to reveal relations within the field and explain the existence of bilingual Khmer/English works in modern contemporary Cambodian literature.

\section{Research Findings}

Literary themes in Cambodian literature have shifted generally from the pastoral themes of Cambodian literature, to the dominance of Buddhist hagiography (Osipov, 2000, p. 1), to the modern free verse and short stories in the contemporary period. The changing of themes is not unintentional but rather it is under influences of agents' relations and position within the field. Cambodia has been trying in developing the existence of their literature on the right track. Some writings continue to reflect the impact of Cambodia difficult past dealing with genocide; nonetheless it is no longer the main concern. "We'd like to proceed, to reach our great literature", said one emerging writer.

The field has indeed changed, compared to the earlier times when the writers stayed within monasteries and lived with high mandarins. In fact, nowadays, they must continually struggle with their own lives because they cannot survive economically relying only upon writing. Most of them hold another job to support themselves, with writing being done in their spare time. However, their direct interactions with society provide them with insights into and ideas about expressing 
inequalities and development gaps in the country. They observe positive traits that enable them to fight for their existence. Without denying their challenging situation, history and the current upheavals, they keep writing.

Government's control over the press has influenced writers' hesitancy in producing literature. A long experience of oppression to critical public discourses toward the government has reached these young writers. Some of them emphasize the importance of awareness about what they should write. Their writings may endanger their families and their lives, similar to how writers in the past were intimidated for what they expressed through their writings. In these circumstances, young writers are required to be more creative either in using metaphors or any other forms of indirect expression in writing. The writers are under pressures, yet they still have a strong insistence to keep writing.

Cambodian literature is growing; however, aid is still needed. The presence of emerging writers in some events, and the works available in the market, are undeniable truth that writers are struggling and learning to shape the literary field. The economic capital of emerging writers is far from adequate to establish their figure at the level of country's representation. They have to accumulate cultural capital, which can be converted into the other forms of capitals within the literary field required to compete.

Potential readership is considerable in order to build literacy in the country. In doing so, Cambodia cooperated with UNESCO and other donor organizations has reached 90\% literacy among youths within the age of 15-25 years old. This demographic circumstance offers optimism for the growth of future literary consumers. Currently, more people are interested in reading, not only in academic texts, but also in literature. Hence, there is a challenge for writers to create a good quality of literature, and for making libraries available to accommodate the need of literature universities, even though it is quite far from a well-developed one.

Several events and organizations exist to promote literacy and literature in Cambodia. The events include Kampot Readers and Writers Festival, Cambodia National Book Fair, Meet Khmer Authors Forum, Meet the Author Seminar, and Creative Writing Training. Literary organizations such as the Nou Hach Literary Association (NHLA), Poets Playwrights Essayists Editors Novelist (PEN) Cambodia, 
Slap Paka Khmer (SPK), Scholar Library, and Cambodia Living Arts (CLA) have created dynamic moves in the contemporary Cambodian field of literature.

\section{Discussion}

Regarding the emergence of bilingual Khmer/English literature, there are three main points to be studied in this analysis. The structure of the literary field in relation to the field of power is important to map out the rules or working principles of the game binding agents and their distribution in the field. Changing in social structures significantly affects agents' dynamic practices based on the 'habitus' attached to them. Emerging writers' strategies and practices get involved in aid organizations and writing bilingual Khmer/English literature. They are also the key elements in the development and transformation of literature in Cambodia.

\section{The Structure of the Literary Field}

In the relations to Cambodian politics and economics, the position of cultural production is still less prioritized. Most attentions under the name of development for the country focus on the physical transformation of the country. This indicates the distance of government intervention from the production of writers and spaces to express writing. According to some emerging writers, there is no direct control from the government, but living discourses of restriction on expression through media, including literature, remain.

The literary field is composed by presence of government ministries, foreign organizations, Cambodian organizations and individuals, supported by related organizations and agents adjacent to the literary field. The involvement is seen in main events, especially the $5^{\text {th }}$ National Book Fair 2016 and Kampot Writers and Readers Festival 2016. The presence of other organizations and individuals are evidenced from smaller-scale activities observed during the research period. These agents are the entity that shapes relations and activities in the Cambodian literary field. Hence, the literary field in Cambodia is built from the relations of agents' positions within it. They consist of individuals that move to create groups and build organizations.

The field of cultural production is entirely within the sphere of power. It is in a dominated position, but also occupies a position of dominance over the literary field. 
This structure is confirmed through observations of the literary production in Cambodia. The field of cultural production is tied to policies made by the ruling government, such as that of shown by discourses on censorship in the media. Such dominance is flexible, sometimes hard and repressive while other times soft and ideological.

At the same time, the literary field can exercise autonomy in making its own rules. The literary field has its own particular conduct, its own chances to organize exclusive activities across nations by using networks with other similar fields outside the country. All agents are bound in the rules of the game, what Bourdieu calls applying the reverse principle of economic materiality on certain situations to accumulate capital. In the literary field, like other fields of art, the symbolic capital of culture is considered more valuable than economic currency. Although the literary field has such characteristics, it is not a guarantee that the field is free from economic principles. All forms of capital will always be at stake, and the situation within the field affects agents' actions and practices.

The literary field remains in contact with larger fields (the field of power, of similar arts) and to smaller subfields (mass production and limited production literature). Agents are constantly interacting to other agents incorporated within other related fields, and through their movements they build inter-agent networks and relations and thereby further shape the structure within the field. Such dynamic practices and strategies make the field keep moving and growing in directions determined by dominating forces or perceived by stronger agents.

Institutions actively building literature in Cambodia, including the Nou Hach Literary Association (NHLA), PEN Cambodia, Slap Paka Khmer, and Khmer Writers Association (KWA), exist in relation to agents in the broader field of cultural production. Cambodian Living Arts, EPIC Arts, and Kampot Arts \& Music Association (KAMA), for example, are not directly related to literature, but getting involved as partners in organizing literary festivals. The publishing industry is important as well, and several Cambodian publishers display the literary works on their book-shelves. Agents at the individual level are replete with young writers who carry their personal names. These young writers such as Channpal Sok, Chhengly Yeng, Chat Piersath, Chin Meas, Phina So, Achariya Hang, and Monica Sok act on behalf of their personal interest. Along with their membership in the fellowships and other 
organizations, they sometimes act on behalf of groups for whom they serve as delegates.

Contestation was observed during the fourth quarter of 2016 in small community discussions, training sessions, forums, informal meetings. The contestation also occurred during the Kampot Readers and Writers Festival 2016, and a year-end gathering of Cambodian writers hosted by Slap Paka Khmer. Within these activities, competition exists between local and foreign agents, as well as between different local agents. More powerful agents structure the literary field, and have the ability to shape the path along which agents follow, at least until they acquire the necessary capital to oppose or change this path.

The literary field in Cambodia has been able to develop sufficiently in the presence of agents that continuously form and maintain relationships through the different positions they occupy. They are the dynamic supporters of the development of the field, particularly the restoring of Cambodian literature. Over time, the autonomy of the literary field has increasingly been shaped in accordance with generally developed art principles. By achieving a fair degree of autonomy, the literary field can better bargain and negotiate, thereby opening more opportunities for the field to grow.

\section{The Changing of Social Structures and Literary Trends in Cambodia}

In terms of general social structures and composition, there has been an important change in Cambodian society and demographics. Before Pol Pot's regime, scholars and academics contributed to control literary production, especially in the monasteries. After the regime's genocide, the literacy rates in society dropped significantly, forcing the nation to rebuild its intelligentsia. Cambodia is now aiming to combat illiteracy in the country. The demographic shows how the structures of educated groups are arising back with more in numbers. Young generation of Cambodia has now easier access to education, which results higher rate of literacy in the society. It is apparent that Cambodia has promising future society with greater chance of living better lives through education.

However, dependence on donor organizations remains high. In the literary field, local agents use foreigners as intellectual companions, though the situation placed locals under domination, especially on quality assurance. Capital transfer has 
distinctively colored the development of literature in Cambodia, including the shift of literary production from monasteries to civilians and donor organizations. This changing structure has contributed to shape the legitimate position of organizations-particularly those with foreign affiliations-to influentially determine which types of works appear in publication.

Literature has not regained its position as high art. The growing Cambodia as a country emphasizes basic food, housing, health, and security needs as its main concerns. Although education has taken a prime position in contributing to the nation's development by promising future intellectuals, it has not had much impact on the growth of literature, as it has remained capital-centrist. Most writers reside in the capital city and are the only icons of hope for the representation of the nation by emerging writers. Changes in social structures, positions of writers in social space, spreads of literature activities, and levels of literacy in society have cumulatively influenced the growth and flourishing of Cambodian literature. However, the presence of foreign aid donors and of poverty in Cambodian society have allowed foreign practices to remain as important factor to the development, while government has taken a certain distance to support the continuing of this situation. Literature is still in the periphery, even compared to other growing performing arts in Cambodia.

Hope for Cambodia's future lies in demographic factors, as most of the country's children now have better access to formal education. Likewise, many young Cambodians have studied abroad with foreign scholarships. The number of intellectuals in Cambodia, as well as their quality, is progressing positively. This might not directly affect the creation of bilingual literature, but does suggest greater promise for international audiences. Increasing usage of English in formal education, presence of expatriates, and rising visitors/ tourists are other supportive factors on greater potential audiences of literature.

Over a longer time span, there has been a trend of combining languages, often with one side in Khmer and the other in another language. The use of a Khmer/French table of contents in the Buddhist Institute's Kambujasuriya, for example, establishes the magazine's identity as a Khmer literary publication, while continuing simultaneously to acknowledge the authority of French as a language (Chigas, 2000, p. 144). Likewise, NHLA has published the sixth, seventh, and eighth 
editions of its journal in Khmer/English, with partial translations of selected titles, as well as a Khmer/English short story anthology. The logical link behind the selection of certain genres is confirmed in the background of Yamada, a researcher in Asian short stories who has tended to take that direction through the publications of her organization (i.e. NHLA).

Since training activities for young writers in Cambodia began, the value of modern literature as perceived through the Western point of view has been delivered by expatriate speakers who serve as keynote speakers. Whether or not there is a direct influence, there is certainly knowledge transfer through such seminars and training sessions. There is definite interaction between speakers and audiences, and young writers and people interested in writing serve as receivers of knowledge. In other words, they are dominated by the source of knowledge, namely the foreign speakers. Thus, this relation gives a clue on account of access, legitimation, and structures of the literary field.

Dominant positions are likewise occupied by foreign academics. The need to use international languages such as English is a slight burden for local individual agents. Nonetheless, Khmer remains used as a means to deliver things to wider audience of intellectuals, and it has not disappeared. Over time, NHLA has negotiated by printing journals in Khmer, but continued to use English. In this situation, the institution has a stronger position because it enjoys access to wider networks and holds the legitimate power to select which works win competitions and deserve display. The translation of a literary work into English thus indicates how Khmerlanguage literary works are simultaneously suppressed and left accessible to the wider community. This treatment suggests a clear direction for the development of literature in Cambodia.

Further evidence is provided by a Khmer/English poetry anthology In the Shadow. Chheangly Yeng selected five poets and published them. The need for this became apparent during the Kampot Writers and Readers Festival 2016, where the foreign audience admired the tonal beauty of Khmer poems when chanted but was unable to understand their meaning. Logically, thus, presenting the poems in a bilingual Khmer/English poetry anthology may contribute to solve the gap.

The language conversion is also evident in the translation of some stories from Khmer to English. The most popular are poems and short stories, but efforts have 
also been made to translate novels. There is also a project for translating Thavry Thon's book A Proper Woman into Khmer, aimed at ensuring more Cambodian women read the works. There has also been a project to translate a story - the English translation of which is titled Goodbye Phnom Penh - from French to Khmer.

Seeing these trends, the language conversion phenomenon supports the existence of bilingual Khmer/English literature. The presence of these two languages in works by active organizations clearly influences other existing works in Cambodia's literary field. At the moment, it bridges emerging writers and foreign forces rebuilding Cambodian literature. There is the possibility that Cambodian literature may become dominated by Khmer, that English-language works will be used to deliver the ideas of Cambodian writers, or that tension will remain on certain situations. In such a situation, the language of literature will continue to rely on strategies seen as best contributing and benefiting the overall growth of literature in Cambodia.

\section{Selected Strategies in the Literary Field}

Strategies used by and practices performed by local agents, in the case of emerging writers, are likely determined by the circumstances of the field described in the previous section. No one can immediately occupy a good position in the literary field without a proper profile. Inferring from activities observed during the research period, visible patterns can be said to show the rules of the game in the Cambodian literary field. First is membership within or affiliation with a community or literary group. This practice grants emerging writers the space to show what is being done related to the production of literary works as well as other activities that support literature. Second is the works themselves, be they publicly online, in print, or currently being written, which provide evidence of agents' contributions to literary productivity and thereby allow agents to be recognized and accepted. Third is achievement; participation in official competitions and attendance at local or international cultural and literary activities enables agents to acquire greater symbolic capital.

Young writers apply to gain funding for training and publication, produce their works with themes of poverty and suffering, and position themselves as juniors who require guidance and whose mistakes - including the failure to meet the 
expectations of literary patrons - are still tolerated. Along with the development of interpersonal networks, several organizations have been formed, including Slap Paka Khmer, which is intended to oversee all writers and serve as a means of voicing the aspirations of society and forming the next generation through literature and writing. Meanwhile, works have been published in a way that pressures the international world to maintain its presence in the field. For example, volumes one through five of the NHLA publications used the Khmer language, while volumes six through eight have been bilingual; NHLA has also published a bilingual short story anthology and two English-language translations. This strategy has also been used by Chheangly Yeng in an effort to increase symbolic capital; one edition of bilingual poetry has been published and another is in progress. This, of course, becomes crucial, as those dominant in the literary arena determines the course of its development.

Establishing social networks with the international community is another important strategy, one that is expected to open more opportunities to present or publish Cambodian literature. Resistance to external pressure was manifested in the Khmer literature festival plan, which was managed by foreigners and only granted little space for local agents. These agents, thus, felt the need to benefit from more solid and real structures.

The positions occupied by local Cambodian agents, with their accomplishments and achievements, are positioned as dominated due to their emerging writers not having been fully acknowledged. It still takes a long time to produce a work and publish it; translation and the expectation that works should be consumed by international audiences adds a new burden. As such, Cambodian literature as a whole is still placed under works of English literature in general, despite continuing efforts to resist such dominance, to improve the quality of works, and to occupy a dominant position within the national scope.

Consciously or not, conversion in the literary field will lead to cultural and symbolic recognition. This is congruent with the autonomy of the literary field as part of the field of cultural production, what Bourdieu calls the economic world reversed. Various generative conversions form the structure of the field among young Cambodian writers. The tendency of social capital to become cultural and symbolic capital, as economic capital remains underdeveloped and incapable of 
meeting writers' needs, is cultivated through institutions with more dominant capabilities.

\section{Conclusion}

Human thinking and action are inherently the manifestation of history. Practices by agents in Cambodian literary field are no exception. Efforts to rebuild the literary field in Cambodia are closely related to discourse of great Cambodian literary tradition. The literature has almost been lost under regime that caused detrimental loss to the nation's population, politics, economy, culture, and social structure. The actions individuated in the lives of particular selves as agents are effective because the powers are structured by, and incorporated, enable collective powers to take place.

Cambodia has space to rebuild literacy through aid from donors focused on providing programs and funds to address the high illiteracy rates within the country. The shift in literary production from religious institutions to civic engagement has offered greater opportunity for significant growth in literary productivity. The era of globalization has provided emerging Cambodian writers with options for presenting their works and choosing their language, literary form, and distribution media.

This situation have had a positive effect and contributed to a new wave of modern and contemporary writings. The historical background of the state and of the consumption of knowledge has shaped the common thematic choices - including humanity, poverty, class disparity, gender inequality, and youth development - used for producing literary works. These, and other current issues, dominate the life experiences and knowledge transmission of Cambodia's emerging writers.

Individual agents in the literary field gain legitimacy by implementing selected strategies. These for example are by learning from seminars, organizing events meant to build literature awareness, and working for organizations involved in the literary field. The conversion of diverse capitals into cultural and symbolic capital is always performed to maintain and improve the acquisition of positions in the literary field.

The emergence of bilingual literature and English-language publications affect the application of western literary aesthetic standards and affect the quality of newly created works in Cambodia. Because of this pressure, the presence of foreign figures 
is very important in legitimizing the existence of agents. Institutions in literary field do not become individual competitors, but serve as media for demonstrating their symbolic and social representation so that individuals have better positions and more opportunities to benefit the growth of literature in Cambodia.

The prospect for developing the literary field in Cambodia appears to be positive. More young people can access literature written in Khmer and in English. The composition of dominant and dominated positions in the Cambodian literary field is sufficient for present needs, in the sense that it shows new writers' seriousness in producing literary works. The strong possession of capitals along with the presence of foreign donors makes it possible for them to influence the development of literature in Cambodia. This is a strong indication that some literary works will continue to be written in English or Khmer/English. The path chosen will depend largely on the dynamic positions of agents in the literary field. Cambodian literature - be it in English, Khmer, or bilingual (Khmer/English) - will continue to be a vital ground for struggled and negotiating as literature continually develops in the country..

\section{References}

Bourdieu, P. (1996). Distinction: A Social Critique of the Judgement of Taste. (R. Nice, Trans.) Cambridge: Harvard University Press.

(1993). The Field of Cultural Production. (R. Johnson, Ed.) U.S.: Columbia University Press.

(1990). In Other Words. (M. Adamson, Trans.) California: Stanford University Press.

. (1986). The Forms of Capital. In J. G. Richardson (Ed.), Handbook of Theory

and Research for Sociology of Education (pp. 47-58). Westport, CT: Greenwood Press.

Brickell, K., \& Springer, S. (Eds.). (2017). The Handbook of Contemporary Cambodia. Oxon: Routledge.

Chandler, D. P. (1993). A History of Cambodia (4th ed.). Chiang Mai: Silkworm Books.

Chigas, G. (2000). The emergence of twentieth century Cambodian literary institutions: the case of Kambujasuriya. In D. Smyth (Ed.), The Canon in Southeast Asian Literatures (pp. 137-138). Richmond: Curzon Press. 
Guillou, A. Y. (2013). Western Aid Workers in Cambodian Hospitals: Ethical, Professional and Social Divergences. South East Asia Research, 21(3), 403-418.

Hart, C. (2011). Doing Literature Review. Los Angeles: SAGE Publications Ltd.

Hine, C. (2005). Virtual Methods. (C. Hine, Ed.) Oxford: Berg. . (2001). Virtual Ethnography. London: SAGE Publications Ltd.

Jacob, J. M. (1996). The Traditional Literature of Cambodia: A Preliminary Guide. Oxford: Oxford University Press.

Jarvis, H., Lalonde, C., \& Lakhena, N. (2006). Publishing in Cambodia. Phnom Penh: JSRC.

Miller, T. (2016). When Nation Loses Its Literature. Retrieved from http://lithub.com/when-a-nation-loses-its-literature/

Nepote, J., \& Dy, K. H. (1981). Literature and Society in Modern Cambodia. In T. S. Chee (Ed.), Essays on Literature and Society in Southeast Asia (p. 61). Kent Ridge: Singapore University Press.

Osipov, Y. M. (2000). Buddhist hagiography in forming the canon in the classical literatures of Indochina. In D. Smyth (Ed.), The Canon in Southeast Asian Literatures (pp. 1-7). Richmond: Curzon Press.

Spradley, J. P. (1980). Participant Observation. U.S.A: Holt, Reinhart and Winston.

Stewart, F., \& May, S. (2004). In the Shadow of Angkor. Hawaii: Manoa.

Strangio, S. (2017). The Media in Cambodia. In The Handbook of Contemporary Cambodia (pp. 76-86). London: Routledge.

Yamada. (2016). Writing from the Margins. In T. Yamada (Ed.), Modern Literature of Cambodia. Phnom Penh: NHLA. . (2013). Short Fiction in Cambodia. In T. S. Yamada (Ed.), "Just a Human Being" and Other Tales from Contemporary Cambodia. Phnom Penh: NHLA. 